\title{
Radionuclide content of, and radiological hazards associated with, samples from the different streams of metal recycling facilities
}

\author{
F.O. Ogundare ${ }^{1}$ and C.U. Nwankwo ${ }^{1,2 \star}$ \\ 1 Physics Department, University of Ibadan, Ibadan, Nigeria. \\ 2 National Institute of Radiation Protection and Research, University of Ibadan, Ibadan, Nigeria.
}

Received 16 July 2014 - Accepted 17 September 2014

\begin{abstract}
Radioactive materials in scrap metals are a radiation protection problem and can become a serious concern when melted in metal recycling facilities. In this study, gamma spectroscopic measurements were carried out on waste from a major metal recycling facility. The activity concentrations $\left(\mathrm{Bq} \cdot \mathrm{kg}^{-1}\right)$ of ${ }^{238} \mathrm{U},{ }^{232} \mathrm{Th},{ }^{40} \mathrm{~K}$ and ${ }^{137} \mathrm{Cs}$ in the samples ranged from $3.60 \pm 0.71-38.05 \pm 2.29,7.07 \pm 2.16-80.42 \pm 10.67,6.89 \pm 1.98-179.22 \pm 6.00$ and $1.69 \pm$ $0.22-2477.76 \pm 9.58$, respectively. The dose rate and annual effective dose ranged from $2.34-134.75 \mathrm{nGy}^{-1} \mathrm{~h}^{-1}$ and $3.28-188.64 \mu \mathrm{Sv}$, respectively. The calculated radium equivalent index values were less than $370 \mathrm{~Bq}$. The implications of these results are discussed.
\end{abstract}

Keywords: Scrap metal / Radioactive contamination / Activity concentration / Effective dose

\section{Introduction}

Waste generated from recycling radioactively contaminated scrap metals is a radiation protection concern for personnel and the public (IAEA, 2012) due to the health implications of exposure to radiation. The elevated radiation levels in the environment reported in many studies carried out on soil and water samples (UNSCEAR, 2008) have been attributed to mainly human activities including metal recycling (AboElmagd et al., 2010; Landsberger et al., 2013).

Radioactivity measurements from these human activities should therefore receive the attention of research communities and regulatory authorities. However, while there have been some reported studies on radioactivity measurement in mining and oil industries, those for scrap metal facilities are very scanty (Kreh and Dewji, 2008; Trotti et al., 2008; Cantaluppi et al., 2012).

In the present work, which is to show that global attention still needs to be focused on radioactivity in recycling facilities, gamma spectroscopic measurements were carried out on samples collected from the different streams of a major scrap metal recycling facility.

\section{Method}

The facility used for the study is an electric arc furnace metal recycling facility, with reports of a high background

\footnotetext{
^ rapuluchi@yahoo.com
}

radiation level, in the Niger Delta Region of Nigeria. Representative samples were collected at the input stream (mixture of soil and scrap metal particles), process stream (near the conveyor belt) and waste streams (slag and furnace dust) of the facility. The samples were dried, ground and then sieved with a 5-mm mesh sieve. About $650 \mathrm{~g}$ of each sample were packed into a Marinelli beaker, tightly closed and sealed, and stored for more than one month to ensure secular equilibrium. Gamma spectrometric measurements were carried out using an ORTEC high-purity germanium detector. The energy and efficiency calibration of the detector was carried out using a 650-g mixed CANBERRA soil standard packed in a Marinelli beaker.

The activity concentration was determined using

$$
A=\frac{N}{\varepsilon \times y \times M \times T}
$$

where $A, N, \varepsilon$ and $y$ are the activity, net count, efficiency and emission probability of the radionuclide, respectively. $M$ is the mass of the sample and $T$ is the counting time (36000 s). Selected gamma lines of ${ }^{228} \mathrm{Ac}$ and ${ }^{208} \mathrm{Tl}$ were used to determine ${ }^{232} \mathrm{Th}$, while ${ }^{214} \mathrm{Bi}$ and ${ }^{214} \mathrm{~Pb}$ were used for ${ }^{238} \mathrm{U}$. Energy lines of $1460.8 \mathrm{keV}$ and $661.7 \mathrm{keV}$ were used for ${ }^{40} \mathrm{~K}$ and ${ }^{137} \mathrm{Cs}$, respectively. The errors associated with the activity concentrations were estimated using

$$
\Delta A=A \times \sqrt{\left(\frac{\Delta N}{N}\right)^{2}+\left(\frac{\Delta \varepsilon}{\varepsilon}\right)^{2}+\left(\frac{\Delta y}{y}\right)^{2}} .
$$


Table 1. Activity concentration (Bq. $\mathrm{kg}^{-1}$ ) of the radionuclides in the waste samples.

\begin{tabular}{|c|c|c|c|c|c|}
\hline Stream & Sample Type & ${ }^{238} \mathrm{U}$ & ${ }^{232} \mathrm{Th}$ & ${ }^{40} \mathrm{~K}$ & ${ }^{137} \mathrm{Cs}$ \\
\hline \multirow{3}{*}{ Waste } & \multirow{3}{*}{ Furnace dust } & $8.69 \pm 2.81$ & $7.07 \pm 2.16$ & $62.91 \pm 3.58$ & $1400.58 \pm 5.92$ \\
\hline & & $13.79 \pm 2.56$ & $15.61 \pm 2.64$ & $64.21 \pm 3.73$ & $436.97 \pm 2.56$ \\
\hline & & $10.28 \pm 2.22$ & $10.95 \pm 2.83$ & $31.54 \pm 2.82$ & $939.39 \pm 4.29$ \\
\hline \multirow{2}{*}{ Waste } & \multirow{2}{*}{ Slag } & $8.22 \pm 0.98$ & $9.89 \pm 1.57$ & $7.62 \pm 1.59$ & $19.18 \pm 0.48$ \\
\hline & & $8.91 \pm 1.28$ & $10.50 \pm 2.10$ & $65.56 \pm 3.82$ & $89.63 \pm 0.95$ \\
\hline \multirow{2}{*}{ Input } & \multirow{2}{*}{ Soil/metal particles } & $10.40 \pm 1.24$ & $13.75 \pm 1.93$ & $24.77 \pm 2.49$ & $55.37 \pm 0.75$ \\
\hline & & $19.31 \pm 2.18$ & $22.41 \pm 2.51$ & $12.66 \pm 3.81$ & $18.05 \pm 0.58$ \\
\hline \multirow{2}{*}{ Process } & \multirow{2}{*}{ Soil/metal particles } & $3.60 \pm 0.71$ & $8.33 \pm 1.10$ & $6.89 \pm 1.98$ & $1.69 \pm 0.22$ \\
\hline & & $38.05 \pm 2.29$ & $80.42 \pm 10.67$ & $89.05 \pm 5.30$ & $54.26 \pm 0.98$ \\
\hline \multirow[t]{4}{*}{ Mould } & Furnace Dust & $8.04 \pm 3.72$ & $10.52 \pm 1.84$ & $179.22 \pm 6.00$ & $2477.76 \pm 9.58$ \\
\hline & AVERAGE & $12.93 \pm 2.00$ & $19.00 \pm 2.94$ & $54.44 \pm 3.51$ & $\mathrm{NC}$ \\
\hline & MINIMUM & $3.60 \pm 0.71$ & $7.07 \pm 2.16$ & $6.89 \pm 1.98$ & $1.69 \pm 0.22$ \\
\hline & MAXIMUM & $38.05 \pm 2.29$ & $80.42 \pm 10.67$ & $179.22 \pm 6.00$ & $2477.76 \pm 9.58$ \\
\hline
\end{tabular}

$\mathrm{NC}=$ Not calculated because of the very large range in values.

The annual effective dose $(E)$ to personnel from external exposure was calculated using

$$
E=D R \times O F \times C F .
$$

$O F$ is the amount of time spent in the contaminated area and assumed to be $2000 \mathrm{hr}_{\mathrm{yr}}^{-1}$. CF is the absorbed dose in air to effective dose conversion factor and is taken to be $0.7 \mathrm{~Sv} \cdot \mathrm{Gy}^{-1}$ (UNSCEAR, 2008). DR, which is the absorbed dose rate, was calculated using

$$
D R=\alpha A_{K}+\beta A_{U}+\gamma A_{T h}+\delta A_{C s} .
$$

Depending on the surface area of the waste heaps facing locations where personnel work, the values of $\alpha, \beta, \gamma$ and $\delta$ were taken from Markkanen (1995). The contribution of $U$ and Th to the committed effective dose $\left(E_{C}\right)$ of the workers was estimated using (UNSCEAR, 2008)

$$
E_{C}=\left(A_{U} e_{U}+A_{T h} e_{T h}\right) D_{L} B_{r} .
$$

$e_{U}$ and $e_{T h}$ are the uranium and thorium effective dose coefficients, respectively. $D_{L}$ and $B_{r}$ are the dust loading factor and breathing rate, respectively. A dust loading of $1 \mathrm{mg} \cdot \mathrm{m}^{-3}$ (IAEA, 2006) is assumed. $e_{U}, e_{T h}$ and $B_{r}$ were taken to be $2.9(55) \mu \mathrm{Sv} . \mathrm{Bq}^{-1}, 25(68) \mu \mathrm{Sv} \cdot \mathrm{Bq}^{-1}$ and $7300 \mathrm{~m}^{3} \cdot \mathrm{yr}^{-1}$ (UNSCEAR, 2008). The radium equivalent index $\left(R a_{\mathrm{eq}}\right)$ was calculated using (Zaidi et al., 1991):

$$
R a_{e q}=A_{U}+1.43 A_{T h}+0.077 A_{K} .
$$

\section{Results and discussion}

\subsection{Activity concentrations}

The activity concentrations are presented in Table 1 for ${ }^{238} \mathrm{U},{ }^{232} \mathrm{Th}$ and ${ }^{40} \mathrm{~K}$, with averages of $12.93 \pm 2.00$,
Table 2. Comparison of NORM activities (Bq. $\mathrm{kg}^{-1}$ ) with literature values.

\begin{tabular}{ccccc}
\hline Sample & \multicolumn{3}{c}{ Radionuclides } & Reference \\
& ${ }^{238} \mathbf{U}$ & ${ }^{232} \mathbf{T h}$ & ${ }^{40} \mathbf{K}$ & \\
\hline \multirow{2}{*}{ Dust } & $3.0-27.0$ & $0.3-11.0$ & $<3.0-6219.0$ & Trotti et al. $(2008)$ \\
& $8.0-13.8$ & $7.1-15.6$ & $31.5-179.2$ & This study \\
\multirow{2}{*}{ Slag } & 950 & 420 & - & Kontol et al. (2008) \\
& $8.2-8.9$ & $9.9-10.5$ & $7.6-65.6$ & This study \\
\hline
\end{tabular}

$19.00 \pm 2.94$ and $54.44 \pm 3.51$ Bq. $\mathrm{kg}^{-1}$, respectively. The concentrations are within previously reported values for soils and their corresponding average values are lower than the world average concentration of $37 \pm 4$ for ${ }^{238} \mathrm{U}, 33 \pm 3$ for ${ }^{232} \mathrm{Th}$ and $400 \pm 24$ for ${ }^{40} \mathrm{~K}$ (UNSCEAR, 2008). All the values are also less than the clearance levels of 1000,1000 and $10000 \mathrm{~Bq} \cdot \mathrm{kg}^{-1}$ (IAEA, 2012) recommended for ${ }^{238} \mathrm{U},{ }^{232} \mathrm{Th}$ and ${ }^{40} \mathrm{~K}$, respectively. This suggests that the activities of the metal recycling facility need not be regulated. The activity of ${ }^{137} \mathrm{Cs}$ ranged from $1.69 \pm 0.22-2477.76 \pm 9.58 \mathrm{~Bq} \cdot \mathrm{kg}^{-1}$. Some of the values were greater than $100 \mathrm{~Bq} \cdot \mathrm{kg}^{-1}$, above which scrap metal recycling is considered unsafe (IAEA, 2012). In agreement with previous reports (IAEA, 2012), activities of ${ }^{137}$ Cs in dust samples are relatively higher than in other samples. Table 2 shows that the activity of the NORM in the dust and slag samples was within the range reported in previous studies (Kontol et al., 2008; Trotti et al., 2008).

\subsection{External dose rates and annual effective dose}

The dose rates due to NORM presented in Table 3 have a mean value of $10.81 \pm 7.17 \mathrm{nGy} \cdot \mathrm{hr}^{-1}$, which is below the world average values (50-59 $\mathrm{nGy}_{\mathrm{hr}}{ }^{-1}$ ) (UNSCEAR, 2008). The annual effective doses ranged from $0.003-0.032 \mathrm{mSv}$. This shows that the effective doses are less than the world average value $(0.066 \mathrm{mSv})$ (UNSCEAR, 2008). Dose rates due to ${ }^{137} \mathrm{Cs}$ 
Table 3. Radium equivalent, dose rates, effective doses and the committed effective dose to the facility's personnel.

\begin{tabular}{|c|c|c|c|c|c|c|c|c|c|}
\hline Stream & Sample type & $\begin{array}{c}\mathbf{R a}_{\mathrm{eq}} \\
\mathrm{Bq} \cdot \mathrm{kg}^{-1}\end{array}$ & $\begin{array}{c}\text { DR(NORM) } \\
\text { nGy.hr' }\end{array}$ & $\begin{array}{c}\text { H(NORM) } \\
\mu \mathrm{Sv}_{\mathrm{yr}}{ }^{-1}\end{array}$ & $\begin{array}{c}\text { DR(Cs) } \\
\text { nGy.hr }{ }^{-1}\end{array}$ & $\begin{array}{c}\mathrm{H}(\mathrm{Cs}) \\
\mu \mathrm{Sv} . \mathrm{yr}^{-1}\end{array}$ & $\begin{array}{c}\text { DR } \\
\text { nGy.hr }{ }^{-1}\end{array}$ & $\begin{array}{c}\mathbf{H} \\
\mu \mathrm{Sv} \cdot \mathrm{yr}^{-1}\end{array}$ & $\begin{array}{c}\text { C. Eff Dose } \\
\mu \text { Sv. } \mathbf{y r}^{-1}\end{array}$ \\
\hline Waste & Furnace dust & $\begin{array}{c}23.60-40.95 \\
(30.95)\end{array}$ & $\begin{array}{c}3.62-8.72 \\
(6.14)\end{array}$ & $\begin{array}{c}5.06-12.21 \\
(8.59)\end{array}$ & $\begin{array}{c}22.72-103.33 \\
(66.3)\end{array}$ & $\begin{array}{c}31.81-144.67 \\
(92.81)\end{array}$ & $\begin{array}{c}28.79-112.05 \\
(72.43)\end{array}$ & $\begin{array}{c}40.32-156.87 \\
(101.4)\end{array}$ & $\begin{array}{c}1.47-3.14 \\
(2.27)\end{array}$ \\
\hline Waste & Slag & $\begin{array}{c}22.86-28.89 \\
(25.878)\end{array}$ & $\begin{array}{c}9.81-12.92 \\
(11.37)\end{array}$ & $\begin{array}{c}13.74-18.09 \\
(15.92)\end{array}$ & $\begin{array}{c}3.07-14.34 \\
\quad(8.71)\end{array}$ & $\begin{array}{c}4.30-20.08 \\
(12.19)\end{array}$ & $\begin{array}{c}12.88-27.26 \\
(20.07)\end{array}$ & $\begin{array}{c}18.04-38.17 \\
(28.1)\end{array}$ & $\begin{array}{c}1.98-2.10 \\
(2.04)\end{array}$ \\
\hline Input & $\begin{array}{l}\text { Soil/metal } \\
\text { particles }\end{array}$ & $\begin{array}{c}31.87-52.17 \\
(42.02)\end{array}$ & $\begin{array}{c}13.77-22.38 \\
(18.07)\end{array}$ & $\begin{array}{c}19.27-31.33 \\
(25.3)\end{array}$ & $\begin{array}{c}2.89-8.86 \\
(5.87)\end{array}$ & $\begin{array}{c}4.04-12.40 \\
\quad(8.22)\end{array}$ & $\begin{array}{c}22.62-25.27 \\
(23.94)\end{array}$ & $\begin{array}{c}31.67-35.37 \\
(33.52)\end{array}$ & $\begin{array}{c}2.73-4.50 \\
(3.61)\end{array}$ \\
\hline Process & $\begin{array}{l}\text { Soil/metal } \\
\text { particles }\end{array}$ & $\begin{array}{c}15.99-159.35 \\
(87.67)\end{array}$ & $\begin{array}{c}2.26-22.62 \\
(12.44)\end{array}$ & $\begin{array}{c}3.16-31.66 \\
(17.41)\end{array}$ & $\begin{array}{c}0.09-2.82 \\
(1.45)\end{array}$ & $\begin{array}{c}0.12-3.95 \\
(2.04)\end{array}$ & $\begin{array}{c}2.34-25.44 \\
(13.89)\end{array}$ & $\begin{array}{c}3.28-35.61 \\
(19.45)\end{array}$ & $\begin{array}{c}1.60-15.48 \\
(8.54)\end{array}$ \\
\hline Mould & Furnace dust & 37.62 & 5.9 & 8.26 & 128.84 & 180.38 & 134.75 & 188.64 & 2.19 \\
\hline \multicolumn{2}{|c|}{ AVERAGE } & 44.16 & 10.81 & 15.13 & 35.98 & 50.37 & 46.79 & 65.50 & 3.74 \\
\hline \multicolumn{2}{|c|}{ MINIMUM } & 15.99 & 2.26 & 3.16 & 0.09 & 0.12 & 2.34 & 3.28 & 1.47 \\
\hline \multicolumn{2}{|c|}{ MAXIMUM } & 159.35 & 22.62 & 31.66 & 128.84 & 180.38 & 134.75 & 188.64 & 15.48 \\
\hline
\end{tabular}

( ) mean value.

ranged from $0.09-128.84 \mathrm{nGy}^{-\mathrm{hr}^{-1}}$, and the annual effective doses ranged from $0.0001-0.18 \mathrm{mSv}$. The total $(\mathrm{NORM}+\mathrm{Cs})$ annual effective dose ranged from $0.003-0.189 \mathrm{mSv}$. The average value $(0.0655 \mathrm{mSv})$ is about the same as the world average value, but below values $(0.08-0.30 \mathrm{mSv})$ reported by Kreh and Dewji (2008) for workers of a recycling facility.

\subsection{Committed Effective Dose and Radium Equivalent Index}

Committed effective doses from annual intake of $U$ and Th, presented in Table 3, ranged from 1.47-15.48 $\mu \mathrm{Sv}_{\mathrm{yr}}{ }^{-1}$. These values are less than the committed effective doses (2.85-5.60 $\left.\mathrm{mSv}_{\mathrm{yr}} \mathrm{r}^{-1}\right)$ reported in the phosphate mining industry, but greater than the maximum effective doses $\left(<0.4 \mu \mathrm{Sv}_{\mathrm{yr}}{ }^{-1}\right)$ from a steel production facility (UNSCEAR, 2008). $\mathrm{Ra}_{\mathrm{eq}}$ presented in Table 3, ranged from 15.99-159.35 Bq. $\mathrm{kg}^{-1}$. The $\mathrm{Ra}_{\mathrm{eq}}$ values were below the recommended value of $37 \mathrm{~Bq} \cdot \mathrm{kg}^{-1}$ (Zaidi et al., 1991). Therefore, the inclusion of the waste in building materials will pose no unacceptable radiological risk. It should, however, be used with caution because of the presence of ${ }^{137} \mathrm{Cs}$.

\section{Conclusion}

NORMs and ${ }^{137} \mathrm{Cs}$ were detected, with ${ }^{137} \mathrm{Cs}$ at a level above the metal recycling clearance level. The calculated total dose rate was greater than the world average. Except for the presence of ${ }^{137} \mathrm{Cs}$, it is radiologically safe to include the waste in building material. The levels of ${ }^{137} \mathrm{Cs}$ suggest the need for increased regulatory supervision of metal recycling activities, especially in developing countries.

\section{References}

Abo-Elmagd M., Soliman H.A., Salman Kh.A., El-Masry N.M. (2010) Radiological hazards of TENORM in the wasted petroleum pipes, J. Environ. Radioact. 101, 51-54.

Cantaluppi C., Ceccotto F., Cianchi A. (2012) Use of natural radionuclide to determine the time range of the accidental melting of an orphan radioactive source in a steel recycling plant, J. Environ. Radioact. 105, 85-87.

IAEA (2006) Assessing the need for radiation protection measures in work involving minerals and raw materials. IAEA Safety Reports Series No. 49. Austria: Publication of International Atomic Energy Agency, STI/PUB/1257.

IAEA (2012) Control of orphan sources and other radioactive material in the metal recycling and production Industries. IAEA safety standards for protecting people and the environment (SSG-17). Austria: Publication of International Atomic Energy Agency, STI/PUB/1509.

Kontol K.M., Ahmad S.H.S.S., Omar M. (2008) Radiological impact assessment fro landfill disposal of NORM waste in Malaysia. In: Proceedings of the fifth international symposium on Naturally Occurring Radioactive Material, Seville, IAEA, the Spanish Nuclear Safety Council and the University of Huelva.

Kreh R., Dewji S. (2008) Estimation of personal dose while processing NORM contaminated metal scrap. In: Proceedings of the fifth international symposium on Naturally Occurring Radioactive Material, Seville, IAEA, the Spanish Nuclear Safety Council and the University of Huelva.

Landsberger S., Brabec C., Canion C., Hashem J., Lu C., Millsap D., George G. (2013) Determination of ${ }^{226} \mathrm{Ra},{ }^{228} \mathrm{Ra}$ and ${ }^{210} \mathrm{~Pb}$ in NORM products from oil and gas exploration: Problems in activity underestimation due to the presence of metals and selfabsorption of photons, J. Environ. Radioact. 125, 23-26.

Markkanen M. (1995) Radiation dose assessments for materials with elevated Natural radioactivity. STUK-B-STO 32, Helsinki 
(A document of Finnish centre for radiation and nuclear safety), p. 19.

Trotti F., Zampieri C., Caldognetto E., Ocone R., Dilullo A., Magro L., Jia G., Torri G. (2008) A study concerning NORM in integrated steel works. In: Proceedings of the fifth international symposium on Naturally Occurring Radioactive Material, Seville, IAEA, the Spanish Nuclear Safety Council and the University of Huelva.
UNSCEAR (2008) Sources and effects of ionizing radiation. 2008 Report to General Assembly with Scientific annexes, Vol. I, New York.

Zaidi J.H., Arif M., Ahmed S., Fatima S., Quresh I.A. (1991) Determination of natural radioactivity in building materials used in the Rawalpindi/Islamabad area by gamma-spectrometry and instrumental neutron activation analysis, Appl. Radiat. Isotopes 51, 559-564.

Cite this article as: F.O. Ogundare, C.U. Nwankwo. Radionuclide content of, and radiological hazards associated with, samples from the different streams of metal recycling facilities. Radioprotection 50(1), 55-58 (2015). 